\title{
In vitro dissolution characteristics of patent, generic and similar brands of naproxen in various dissolution media
}

\author{
María F Rocha-Alcaraz ${ }^{1}$, Erandis D Torres-Sánchez ${ }^{1}$, Juan H Torres-Jasso², \\ Alán Y Yáñez-González ${ }^{1}$, Mireya Z Reyna-Villela ${ }^{3}$, Daniel Rojas-Bravo ${ }^{3}$, Joel \\ Salazar-Flores ${ }^{1 *}$ \\ ${ }^{1}$ Department of Medical Sciences and Life, Cu-Ciénega, ${ }^{2}$ Department of Biological Sciences, Division of Biological and Health \\ Sciences, Cu-Coast, ${ }^{3}$ Department of Technological Cu-Ciénega, University of Guadalajara, Jalisco, México
}

${ }^{\star}$ For correspondence: Email: joelos12@hotmail.com; Tel: (+52) 3929257112

Sent for review: 2 February 2019

Revised accepted: 24 May 2019

\begin{abstract}
Purpose: To investigate the dissolution properties of various brands of naproxen in four dissolution media in order to forecast their biological availability.

Methods: Dissolution tests were carried out in a dissolution tester with 48 tablets of different naproxen brands in $900 \mathrm{~mL}$ of $0.1 \mathrm{M}$ phosphate buffer, $\mathrm{pH}$ 7.4. Subsequently, the medium was modified with 600 $\mathrm{mL}$ of buffer plus $300 \mathrm{~mL}$ of cola drink, grapefruit or milk. Each sample was taken and brought to a concentration approximating that of a reference solution. Absorbance at $332 \mathrm{~nm}$ was determined and the dissolution, $Q$, was calculated ( $Q$ values $\geq 80.0 \pm 5 \%$ were acceptable).

Results: Dissolution in buffer was $>85 \%$. In cola drink, it was $<80 \%$, while in grapefruit juice, it was in the range of $7-68 \%$. Using 2-way ANOVA, these media and the three naproxen brands showed significant differences $(F=68.90, p=0.0000 ; F=23.18, p=0.0000)$. With Fisher's $L S D$ test, two of these media contributed consistently to dissolution, and the three drug brands showed statistically different dissolution profiles ( $p \leq 0.05$ ).

Conclusion: Caution must be exercised cola drink, grapefruit juice and milk are used to administered naproxen as the biological availability of the drug may be altered.
\end{abstract}

Keywords: Naproxen brands, Dissolution, Phosphate buffer, Grapefruit, Cola drink, Milk

This is an Open Access article that uses a fund-ing model which does not charge readers or their institutions for access and distributed under the terms of the Creative Commons Attribution License (http://creativecommons.org/licenses/by/4.0) and the Budapest Open Access Initiative (http://www.budapestopenaccessinitiative.org/read), which permit unrestricted use, distribution, and reproduction in any medium, provided the original work is properly credited.

Tropical Journal of Pharmaceutical Research is indexed by Science Citation Index (SciSearch), Scopus, International Pharmaceutical Abstract, Chemical Abstracts, Embase, Index Copernicus, EBSCO, African Index Medicus, JournalSeek, Journal Citation Reports/Science Edition, Directory of Open Access Journals (DOAJ), African Journal Online, Bioline International, Open-J-Gate and Pharmacy Abstracts

\section{INTRODUCTION}

Naproxen is one of the most frequently prescribed non-steroidal anti-inflammatory drugs (NSAIDs) in the world. It is slightly soluble in water $\left(25 \mathrm{mg} / \mathrm{L}\right.$ at $\left.25^{\circ} \mathrm{C}\right)[1,2]$. Thus, it has a low degree of dissolution which affects its bioavailability and bioequivalence. The degree of dissolution can predict the availability of a drug and its consistency from one lot to another [3].

It is also important to determine the bioavailability of drugs administered orally, as well as their bioequivalence and interchangeability [4]. If the preferred route of administration is oral, it is important that oral dissolution and absorption of the drugs should be guaranteed. In vitro 
dissolution tests are officially used to demonstrate drug release, and should be evaluated periodically, at least in generics and similar drug forms [5,6]. If the differences between generic and patent medicines are due to inactive ingredients, and if some generic formulations eliminate qualitatively and, sometimes quantitatively, the excipients of the patent formulation, then this can affect their interchangeability [7].

Regarding similar drugs, it is known that they are generic preparations, which have not passed bioequivalence and bioavailability tests, but have emerged as successful commercial strategy, which has made a business model in Mexico and Latin America [8]. Although most drugs fulfill the pharmacopoeia dissolution criteria, some generics differ from patent forms, or even differ amongst themselves [9]. The objective of this study was to evaluate the in vitro percentage dissolution of patent, generic and similar forms of naproxen in different dissolution media that could alter their speed of dissolution.

\section{EXPERIMENTAL}

\section{Preparation of dissolution medium (0.1 M phosphate buffer, pH 7.4)}

Monobasic sodium phosphate (2.62 g, Jalmek Científica $(\mathbb{B})$ and $11.50 \mathrm{~g}$ of anhydrous sodium dibasic phosphate (Jalmek Científica®) were weighed and transferred to a $1000 \mathrm{~mL}$ volumetric flask, where they were dissolved in water. The $\mathrm{pH}$ of the buffer was adjusted to 7.4 at $37^{\circ} \mathrm{C}$ [9].

\section{Preparation of reference solution $(50 \mu \mathrm{g} / \mathrm{mL}$ naproxen in $0.1 \mathrm{M}$ phosphate buffer, $\mathrm{pH}$ 7.4)}

This reference solution was prepared by dissolving $10 \mathrm{mg}$ of the active ingredient (Naproxen sodium, Jalmek®) in $10 \mathrm{~mL}$ of $0.1 \mathrm{M}$ phosphate buffer, $\mathrm{pH} 7.4$, in a $10-\mathrm{mL}$ volumetric flask. Then, $2.5 \mathrm{~mL}$ of the solution was made up to $50 \mathrm{~mL}$ in a $50-\mathrm{mL}$ volumetric flask with the same phosphate buffer solution (MGA 0291) [9]. Finally, the absorbance of the reference solution was determined at a wavelength of $332 \mathrm{~nm}$.

\section{Dissolution test in different media}

To determine the percentage dissolution in phosphate solution medium, one 550-mg tablet of patent naproxen, generic or similar was put in a Logan UDT-804 dissolution tester well containing $900 \mathrm{~mL}$ of phosphate solution as dissolution medium, and the instrument was allowed operate at $50 \mathrm{rpm}$ for $45 \mathrm{~min}$ (MGA 0291) [9]. The test was repeated using only 600
$\mathrm{mL}$ of phosphate solution and $300 \mathrm{~mL}$ of cola drink, grapefruit juice or pasteurized whole milk, under the same conditions.

At the end of each test (buffer, cola drink, grapefruit and milk), $10 \mathrm{~mL}$ of solution was filtered from each well, and $2.1 \mathrm{~mL}$ was taken and placed in a $25-\mathrm{mL}$ volumetric flask that was gauged, in order to obtain a theoretical concentration approximate to that of the reference solution $\quad(50 \quad \mu \mathrm{g} / \mathrm{mL}$ naproxen/phosphate solution, $0.1 \mathrm{M} \mathrm{pH} 7.4)$. The absorbance was determined at $332 \mathrm{~nm}$ in a spectrophotometer with $1 \mathrm{~cm}$ cells, using phosphate solution as an adjustment target. The percentage dissolution of naproxen (Q) was calculated using Eq 1.

$Q=\left\{100 C D\left(A_{m} / A_{r e f}\right)\right\} / M$

where $C$ is the amount of naproxen per $\mathrm{mL}$ in the reference solution, $D$ the dilution factor of the sample, $M$ the concentration of naproxen indicated on the label, $A_{m}$ is the sample absorbance, while $A_{\text {ref }}$ is the absorbance of the reference solution $(Q \geq 80.0 \% \pm 5 \%$ are acceptable for a stage $S 1$ [9].

The dilution factor $(D)$ was calculated using Eq 2.

$D=\left\{\left(N T / V_{m}\right)\left(V_{f} / V_{a}\right)^{-1}\right\}$

where $D$ is the dilution factor of the sample, NT is the number of tablets tested (1), $V_{m}$ is volume of the dissolution medium $\left(900 \mathrm{~mL}, V_{f}\right.$ is the filtered volume $(2.1 \mathrm{~mL})$, and $V_{a}$ is the volume of the dilution $=25 \mathrm{~mL}$

In order to check the consistency of the results, the test was carried out in duplicate ( 6 tablets per test) in each drug brand, which resulted in the analysis of a total of 48 tablets (12 for each medium: buffer, cola drink, grapefruit and milk). In each medium, the three types of medication (patent, generic and similar) were analyzed.

\section{Statistical analysis}

The data were analyzed with SPSS statistical software v19.0 [10]. Descriptive statistics such as mean $\pm S D$, range, and percentage dissolution of the different brands in the three dissolution media, were obtained. To determine statistically significant differences in dissolution of drug brands in the different media, and the interaction between them, a 2-way analysis of variance was used. Multiple Range test (Fisher's LSD test) was applied to determine homogeneity in the dissolution media and the different drug brands. The significance level for each test was set at $p<$ 
0.05 and two tails. The coefficient of variation (\% $\mathrm{CV}$ ) was calculated to determine if samples of the buffer medium complied with the provisions of "Farmacopea de los Estados Unidos Mexicanos" (FEUM); CV $\leq 3 \%$ [9].

\section{RESULTS}

The data obtained from the percentage dissolution of patent naproxen (Figure 1), generic naproxen (Figure 2) and similar naproxen (Figure 3 ) in the three media presented lower values than the pharmacopoeia limits acceptable to FEUM. It should be noted that with the medium rich in milk, it was not possible to obtain relevant data due to the interference of milk with the absorbance readings. The analyses with cola drink, grapefruit juice and milk were carried out with the purpose of investigating if the dissolution was modified by the natural properties of these media.

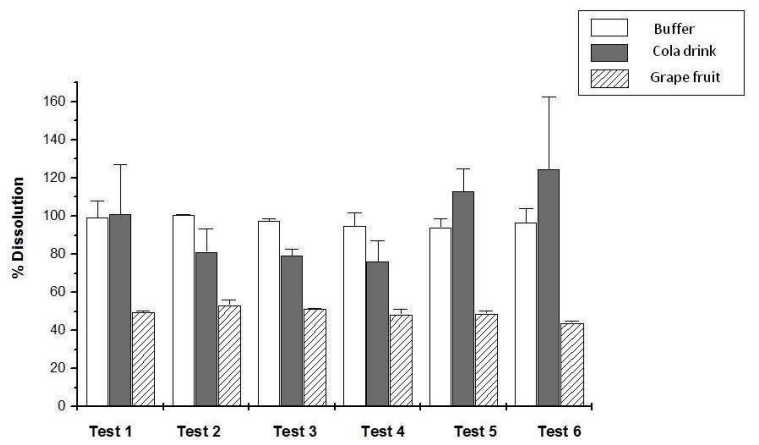

Figure 1: Dissolution of patent naproxen in different media. The results of all 6 tests in buffer medium satisfied the dissolution percentage specified in FEUM. In cola medium, tests 3 and 4 showed a slightly lower value of $80 \%$, while in grapefruit juice all tests presented lower values than the accepted pharmacopoeia limits in FEUM

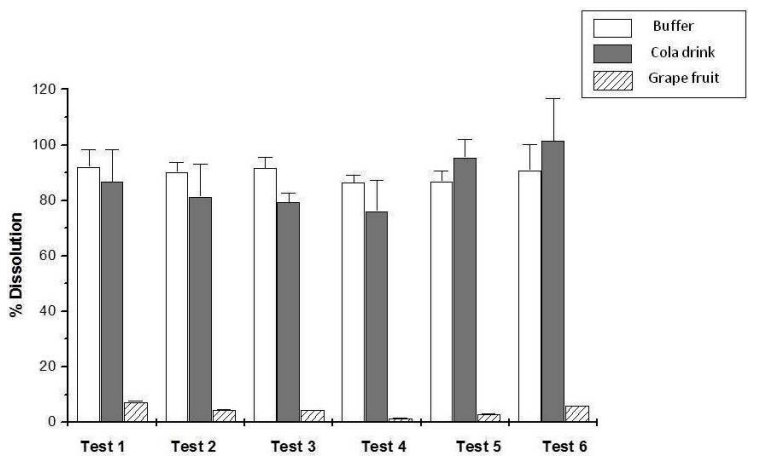

Figure 2: Dissolution percentage of generic naproxen in different media. Results from all 6 tests in buffer medium satisfied the dissolution percentage specified in FEUM, while in cola medium, tests 3 and 4 showed values slightly lower than $80 \%$. In grapefruit juice, all the tests presented lower values than the accepted pharmacopoeia limits in FEUM

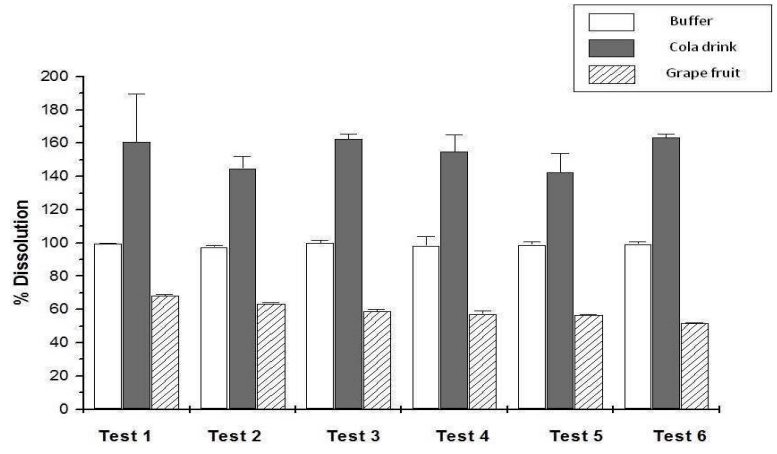

Figure 3: Dissolution of similar naproxen. The results of all the 6 tests in buffer medium satisfied the specified dissolution percentage in the FEUM. Ditto for cola drink, but with higher values than $100 \%$ of the dissolution percentage. In grapefruit juice, all the tests presented lower values than the pharmacopoeia limits acceptable to FEUM

\section{Dissolution in phosphate buffer}

Results from phosphate buffer complied with the dissolution percentage established in FEUM ( $Q \geq$ $80 \pm 5 \%$, with a range of 86.9 to $100.7 \%$ ), both for the patent (Figure 1), generic (Figure 2) and similar naproxen (Figure 3). The results were consistent in the three analyzed products, in line with the FEUM criteria. CV which was $<3 \%$ for all samples was also obtained as indicated in Table 1.

In the patent and generic product tests, the percentage dissolutions were $<80$ for 2 out of 6 tests (Figures 1 and 2, tests 3 and 4 , respectively). The similar drug and most of the patent and generic tests (except 3 and 4) yielded values $>80 \%$ (Figure 3 ).

\section{Dissolution in grapefruit juice medium}

For all the products analyzed, the results were less than $80 \%$. The lowest value was observed in generic naproxen, with a range of 1 to $7 \%$ (Figure 2). The highest values were obtained with the similar brand (Figure 3), with percentage dissolution in the range of 51 to $68 \%$. The most consistent dissolution results were observed with patent naproxen (Figure 1) and similar brand (Figure 3), while a lower range was obtained with the generic product (Figure 2).

\section{Dissolution in milk-rich medium}

It was not possible to calculate the dissolution percentage due to the natural turbidity of milk which resulted in interference with absorbance readings. However, complete dissolution of the tablets was observed in the dissolution tester flasks. 
Table 1: Pharmacopoeial acceptance criteria for dissolution of patent, generic and similar naproxen in buffer medium

\begin{tabular}{lcccccc}
\hline Drug brand & Stage & $\begin{array}{c}\text { Number of } \\
\text { units }\end{array}$ & $\begin{array}{c}\text { Mean } \\
\text { percentage } \\
\text { dissolved }\end{array}$ & $\begin{array}{c}\text { Acceptance } \\
\text { criteria } \\
\text { FEUM, 2016 }\end{array}$ & $\begin{array}{c}\text { Accomplish } \\
\text { FEUM, 2016 }\end{array}$ & CV (\%) \\
\hline Patent & S1 & 6 & $97.1558 \%$ & Q $+5 \%$ & $\checkmark$ & 2.6109 \\
Generic & S1 & 6 & $90.0875 \%$ & Q $+5 \%$ & $\checkmark$ & 2.4804 \\
Similar & S1 & 6 & $99.0058 \%$ & Q $+5 \%$ & $\checkmark$ & 0.8506 \\
\hline
\end{tabular}

Two-way ANOVA (medium/brand) and its contribution towards dissolution

The variance analysis of two factors i.e. media and drug type and its contribution to percentage dissolution, is shown in Figure 4. The dissolution media (buffer, grapefruit juice and cola drink) and drug brand showed significant values $(F=68.90$, $p=0.0000$ and $F=23.18, p=0.0000$ respectively). In evaluating the interaction between both factors, a significant value was also obtained ( $F=6.97, p=0.0002)$. In order to find out which medium and drug brand accounted for the differences, a multiple range test was performed (Fisher's LSD Test). The results showed two homogeneous groups for the dissolution medium (buffer and cola), and three heterogeneous groups for the drug brand ( $p \leq$ 0.05; Figure 4).
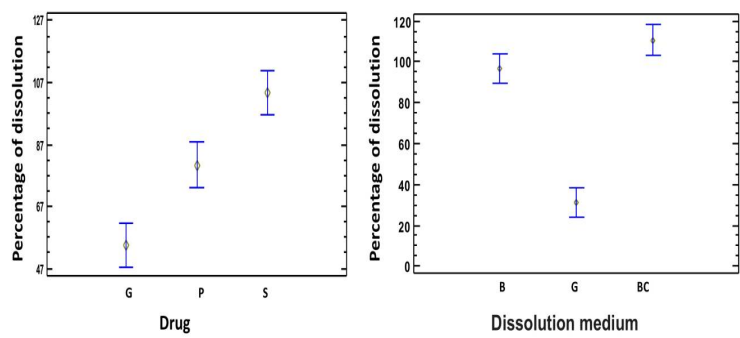

Figure 4: Multiple range chart. Clusters are shown for the dissolution media type ( $B=$ buffer; $G=$ grapefruit juice; $C=$ cola drink) and the drug brand ( $P=$ patent; $\mathrm{G}=$ generic and $\mathrm{S}=$ similar)

\section{DISCUSSION}

The solution medium with phosphate buffer stabilizes $\mathrm{pH}$ and osmolarity in a way that mimics the isotonic nature of the human body [11], creating a favorable environment to dissolve naproxen. In this study, values of $Q>80 \pm 5 \%$ were obtained for the patent, generic and similar brands of naproxen. Thus, the three brands of naproxen fulfilled the FEUM specification for an in vitro medium with similar conditions to those of the human stomach. With respect to CV (range, 0.85 to $2.61 \%$ ), this medium also complied with the provisions of FEUM.
Cola drink medium is a carbonated beverage rich in phosphoric acid and sodium citrate, and smaller amounts of sodium benzoate, as well as sweeteners e.g. aspartame. The highly acidic nature of this medium enhances its organoleptic properties. Carbonation influences $\mathrm{pH}(2.3$ to 2.6), resulting in carbonic acid which gives acid media [12]. The excipients contained in naproxen tablets are cellulose, sodium lauryl sulfate, magnesium stearate and sodium carboxymethyl starch, which are susceptible to erosion in an acidic environment. This may explain the high dissolution percentage in tests $1(100.98 \%), 5$ $(113 \%)$ and $6(124.5 \%)$ of the patent drug, and in test $5(95 \%)$ and test $6(101.5 \%)$ of the generic brand.

However, in the similar brands, since they do not have any of these excipients or have them in a low concentration [7], they can also be highly soluble, which is consistent with the results obtained here. The lowest dissolution percentages were shown by the patent and generic forms of naproxen. There is evidence that at higher concentrations of phosphoric acid, there is higher hydrolysis of cellulose, a basic ingredient used as excipient in the products analyzed [13].

With respect to the CV (range of 21 to $5 \%$ ), the results obtained with this medium do not comply with the provisions of FEUM. However, this medium need not strictly fulfill these provisions since the FEUM criteria are for an in vitro environment with similar conditions to those of the human intestine (buffer). Nonetheless, this test provides an initial evidence that a different medium can modify the percentage dissolution and the release of a drug. When the test was repeated, the results were consistent. However; since this medium is not considered in FEUM as a medium similar to the human stomach conditions, only stage S1 was made, and it was non-compliant.

The greatest variability in the value of $Q$ for all the presentations of naproxen (patent, generic and similar) was observed in the grapefruit juice medium. The main components of grapefruit are flavonoids with antioxidant compounds such as 
hesperidin, naringin, rutin and ascorbic acid [14]. Most studies on the effect of grapefruit on drugs focused on its metabolic interaction with cytochrome P-450 3a4, without evaluating the effect it has on the dissolution of these drugs [15].

However, previous studies have reported that low $\mathrm{pH}$ values affect the polymer chain by hydrolyzing the glucosidic bonds of cellulose, which causes the degradation of the excipient in the tablet [16]. Thus, higher dissolution values were expected, contrary to what was observed. Indeed, this medium presented the lowest dissolution values. It is possible that the chemical interaction of agglutination occurred between the highly hydrophobic active principle and the proton-rich milieu of the grapefruit medium, thereby decreasing the $Q$ value expected $(\geq 80$ $\%)$. It should be noted that in the dissolution tester flask, there were tablet remnants. Therefore, it may be assumed that manufacturing factors influenced the dissolution, and probably, the agglutination of the product. Like the cola drink medium, grapefruit juice is not considered in FEUM as a medium similar to the human stomach conditions. Thus, it is not expected to meet its criteria. Only one stage S1 was performed.

In the milk-rich medium tests, the absorbance values could not be accurately determined, due to the interference from the turbidity of the medium. This is as a result of high concentrations of proteins, lipids and minerals in dairy products [17], and the interaction of the medium components with casein, forming structural complexes that hinder proper readings [18]. As in the previous two tests, only stage S1 was carried out.

Regarding the multi-range test, a statistical difference was observed when contrasting the buffer-grapefruit and grapefruit-soda drink media. Therefore, it was deduced that grapefruit juice significantly altered the percentage dissolution of naproxen. However, it is necessary to carry out more studies to confirm this assumption, since grapefruit juice is a complex natural product consisting of three main chemical substances: furanocoumarins (bergamotine and 6,7,dihydroxibergamotine), flavanones (naringenin, naringin, hesperidin) and polimethoxiflavones (tangeretina and nobiletina) [19]. Naringin constitutes approximately $70 \%$ of the flavonones in grapefruit juice, while the remaining $30 \%$ comprises hesperidin and naringenin. Naringin and hesperidin react poorly with compounds of low solubility (such as naproxen). This may explain the agglutination of the tablets observed in the dissolution tester flasks [20].

In the analysis of the effect of drug type (patent, generic or similar) on dissolution, a statistically significant difference was obtained. This agrees with the results of another study in which the dissolution of some NSAIDs was also analyzed. In the present study, the generic drugs were diluted differently from the patent form [5]. With respect to the similar brand, this is probably the first study to report differences in dissolution between different media, as preliminary evidence that medium components affect percentage dissolution. This may question the interchangeability between patent, generic and similar drugs [5].

However, it should be mentioned that, one of the main limitations of this study was that the methodology used is for determining pharmacopoeia limits using buffer as a medium, but it is not suitable for modified media containing other components such as drink cola, grapefruit juice or milk. However, it is believed that this test can demonstrate that in vitro dissolution with modified media can be used to confirm alterations in the dissolution of drugs administered orally.

\section{CONCLUSION}

In vitro dissolution media modified with cola drink, grapefruit juice or milk show alterations in the dissolution characteristics of naproxen. More studies are needed to confirm these results in vivo. Nonetheless, these findings reveal that these foods/media might alter the biological availability of drugs administered orally, as well as the consistency and interchangeability of drugs from one lot to another.

\section{DECLARATIONS}

\section{Conflict of interest}

No conflict of interest is associated with this work.

\section{Contribution of authors}

We declare that this work was done by the author(s) named in this article and all liabilities pertaining to claims relating to the content of this article will be borne by the authors. We recognize Rocha-Alcaraz MF and Yáñez-González AY for their valuable participation in practical laboratory work. We also recognize Reyna-Villela, MZ and Rojas-Bravo, D for their valuable contribution in 
the design of the study and technical support in the laboratory. Torres-Sánchez ED and SalazarFlores $\mathrm{J}$ analyzed the data and wrote the article and Torres-Jasso $\mathrm{JH}$, reviewed and participated as a proofreader in the English language of this manuscript. All authors read and approved the manuscript for publication.

\section{Open Access}

This is an Open Access article that uses a funding model which does not charge readers or their institutions for access and distributed under the terms of the Creative Commons Attribution License (http://creativecommons.org/licenses/by/ 4.0) and the Budapest Open Access Initiative (http://www.budapestopenaccessinitiative.org/rea d), which permit unrestricted use, distribution, and reproduction in any medium, provided the original work is properly credited.

\section{REFERENCES}

1. Corti G, Maestrelli F, Cirri M, Mura P, Zerrouk N. Dissolution and permeation properties of naproxen from solid-state systems with chitosan. Drug Deliv 2008; 15(5): 303-312.

2. Amidon GL, Lennernäs $H$, Shah VP, Crison JR. A Theoretical Basis for a Biopharmaceutic Drug Classification: The Correlation of in Vitro Drug Product Dissolution and in Vivo Bioavailability. AAPS J 1995; 16(5): 894-898.

3. Guo JH, Harcum WW, Skinner GW, Dluzneski PR, Trumbull DE. Validation of tablet dissolution method by high-performance liquid chromatography. Drug Dev Ind Pharm 2000; 26(3): 337-342.

4. Löbenberg $R$, Amidon GL. Modern bioavailability, bioequivalence and biopharmaceutics classification system. New scientific approaches to international regulatory standards. Eur J Pharm Biopharm 2000; 50(1): 3-12.

5. Al Ameri MN, Nayuni N, Anil Kumar KG, Perrett $D$, Tucker A, Johnston A. The differences between the branded and generic medicines using solid dosage forms: In-vitro dissolution testing. Results Pharma Sci 2011; 2: 1-8.

6. Kostewicz ES et al. In vitro models for the prediction of in vivo performance of oral dosage forms. Eur J Pharm Sci 2014; 57: 342-366
7. Garcia AA, Hernandez GC, Avendaño SC. Regulación de los medicamentos genéricos : evidencias y mitos. Inf Ter Sist Nac Salud 2010; 34: 71-82.

8. Dominguez PDA, Pérez RMN. Los medicamentos similares: ¿una nueva clase de medicina o sólo una estrategia comercial?. Mundo Siglo XXI 2009; 18: 7786.

9. Farmacopea de los estados Unidos Mexicanos, 2016. [Online]. Available at: [https://www.farmacopea.org.mx/ Repositorio/Documentos/302.pdf]

10. SPSS Inc. Released 2010. SPSS for Windows, version 19.0 Chicago, SPSS Inc.

11. Raffaella A, Petrescu RVV, Antonio A, Petrescu FIT. Physiologic human fluids and swelling behavior of hydrophilic biocompatible hybrid ceramo-polymeric materials. AJEAS 2016; 9(4): 962-972

12. Cochrane NJ, Cai F, Yuan Y, Reynolds EC. Erosive potential of beverages sold in Australian schools. Aust Dent J 2009; 54(3): 238-244.

13. Percival Zhang $Y H$, Jingbiao $C$, Lynd LR, Kuang LR. A transition from cellulose swelling to cellulose dissolution by o-phosphoric acid: Evidence from enzymatic hydrolysis and supramolecular structure. Biomacromolecules, 2006; 7(2): 644-648.

14. Wu T, Quan YQ, Ye J. Determination of flavonoids and ascorbic acid in grapefruit peel and juice by capillary electrophoresis with electrochemical detection. Food Chem 2007; 100: 1573-1579.

15. Kane GC, Lipsky JJ. Drug-grapefruit juice interactions. Mayo Clin Proc 2000; 75(9): 933-942.

16. Lindman B, Karlström G, Stigsson L. On the mechanism of dissolution of cellulose. J Mol Liquids 2010; 156: 7681.

17. Kaur J, Katopo L, Ashton J, Whitson A, Kasapis S. Molecular interactions of milk protein with phenolic components in oat-based liquid formulations following UHT treatment and prolonged storage. J Sci Food Agric 2018; 98(5): 1794-1802.

18. Stefanescu R, Brebu S, Matei M, Risca IM, Surleva A, Drochioiu G. Contribution to Casein Determination by UV Spectrophotometry. Acta Chemica lasi 2017; 25(2): 112-126.

19. Johnson EJ, Won CS, Köck K, Paine MF. Prioritizing pharmacokinetic drug interaction precipitants in natural products: application to OATP inhibitors in grapefruit juice. Biopharm Drug Dispos 2017; 38(3): 251-259.

20. Cartaya O, Reynaldo I. Flavonoides: características químicas y aplicaciones. Cultivos Tropicales 2001; 22(2): 5-14. 